Semin Radiat Oncol. 2014 July ; 24(3): 181-191. doi:10.1016/j.semradonc.2014.02.007.

\title{
MRI-guided brachytherapy
}

\author{
Kari Tanderup, $\mathrm{PhD}^{1,2}$, Akila Viswanathan, MD, $\mathrm{MPH}^{3}$, Christian Kirisits, DSc ${ }^{4}$, and Steven \\ J. Frank, MD ${ }^{5}$ \\ ${ }^{1}$ Department of Radiation Oncology, Washington University School of Medicine, St. Louis, \\ Missouri, USA \\ 2Department of Oncology, Aarhus University Hospital, Aarhus, Denmark \\ ${ }^{3}$ Department of Radiation Oncology, Dana-Farber Cancer Institute/Brigham and Women's \\ Hospital, Boston, Massachusetts, USA \\ ${ }^{4}$ Department of Radiotherapy and Oncology, Comprehensive Cancer Center \& Christian Doppler \\ Laboratory for Medical Radiation Research for Radiation Oncology, Medical University of Vienna, \\ Vienna, Austria \\ ${ }^{5}$ Department of Radiation Oncology, The University of Texas MD Anderson Cancer Center, \\ Houston, Texas, USA
}

\section{Abstract}

The application of MRI-guided brachytherapy has demonstrated significant growth during the last two decades. Clinical improvements in cervix cancer outcomes have been linked to the application of repeated MRI for identification of residual tumor volumes during radiotherapy. This has changed clinical practice in the direction of individualized dose administration, and mounting evidence of improved clinical outcome with regard to local control, overall survival as well as morbidity. MRI-guided prostate HDR and LDR brachytherapy has improved the accuracy of target and organs-at-risk (OAR) delineation, and the potential exists for improved dose prescription and reporting for the prostate gland and organs at risk. Furthermore, MRI-guided prostate brachytherapy has significant potential to identify prostate subvolumes and dominant lesions to allow for dose administration reflecting the differential risk of recurrence.

MRI-guided brachytherapy involves advanced imaging, target concepts, and dose planning. The key issue for safe dissemination and implementation of high quality MRI-guided brachytherapy is establishment of qualified multidisciplinary teams and strategies for training and education.

\section{Introduction}

Magnetic resonance imaging (MRI) is an important imaging modality for management of oncologic disease. With its excellent soft-tissue contrast, MRI is used for staging, treatment planning, monitoring of treatment response and surveillance after treatment in many cancer

Corresponding author: Kari Tanderup, PhD, Department of Radiation Oncology, Washington University School of Medicine, 4921, Parkview Place, Campus Box 8224, St. Louis, MO 63110, USA. Phone: 314-747-7164. Fax: 314-747-5735.

ktanderup@radonc.wustl.edu. 
sites. For many years, x-ray imaging, computed tomography (CT), and ultrasound (US) have been the preferred imaging modalities for cervix and prostate brachytherapy treatment planning. However, the last two decades have witnessed an increasing access to MRI and an increasing use of MRI for brachytherapy treatment planning.

The cervix is among the first cancer sites where response-adaptive radiotherapy has been successfully implemented in clinical practice. MRI at the time of brachytherapy allows the brachytherapy boost to be individually tailored according to the residual tumor volume after typically 40-50 Gy of external beam radiation therapy (EBRT). This new approach has changed patterns of clinical practice with regard to dose administration (1-3), and significant improvements in clinical outcome have already been reported from monoinstitutional settings with regard to local control, overall survival and morbidity $(1 ; 4 ; 5)$. Currently, there is a considerable interest in the community to implement MRI-guided brachytherapy in cervix cancer. The step from $2 \mathrm{D}$ x-ray to $3 \mathrm{D}$ image-guided adaptive brachytherapy is based on the development of new concepts for target definition and reporting by the GEC ESTRO working group (6; 7). These concepts are further developed in the upcoming ICRU report on cervix cancer brachytherapy, and recommendations from GEC ESTRO and ABS have been published to support the implementation of the 3D IGABT technique in an increasing number of institutions (8-11).

High quality prostate brachytherapy follows a standard six-step process; patient selection, simulation, treatment planning, implant, post-implant assessment, and follow-up/ surveillance. Anatomic MRI provides the optimal soft-tissue delineation of the prostate from surrounding organ structures and provides a view of the intraprostatic anatomy that is unparalleled with either ultrasound or computed tomography. The role of MRI in each step of the six-step process of quality assurance has still not been standardized. However, MRIguided prostate brachytherapy is rapidly evolving due to the technological advances in MRI protocol sequence development for MRI-guided biopsy and staging, simulation, treatment planning, implant, and post-implant dosimetry. In particular, MRI has been implemented into the prostate brachytherapy procedure due to the excellent visibility of the prostate gland and capsule in MRI as compared to CT and US $(12 ; 13)$. Furthermore, the visualization of normal tissue is superior, and incorporation of MRI into prostate brachytherapy has the potential to improve dose assessment and to limit dose to organs at risk (OAR) $(13 ; 14)$.

This paper reviews the application and status of MRI-guided brachytherapy with a focus on gynecologic and prostate cancers, which are the major indications for MRI-guided brachytherapy. The role of MRI for screening, biopsy, diagnosis, and staging of gynecologic and genitourinary tumors is beyond the scope of this manuscript, and the paper will focus on the major steps specific to MRI-guided brachytherapy: clinical application, imaging, and treatment planning. Furthermore, the paper addresses the first promising outcome results from MRI-guided brachytherapy, as well as the prospects of MRI-guided brachytherapy to further improve clinical outcome. 


\section{Clinical approach}

\section{Gynecologic cancer}

Upon presentation to the physician, patients with gynecologic malignancies undergo a thorough clinical examination and, optimally, diagnostic MRI. The most common gynecologic diagnoses for which a pelvic MRI is obtained include cervical, vaginal and recurrent endometrial cancer. At the time of brachytherapy, MRI can be obtained in addition to clinical examination for assessment of response and residual tumor (Fig. 1). The regression demonstrated by MRI after 45 Gy EBRT compared to the baseline MRI has been shown to be a potentially significant predictor of local recurrence (15). 3D imaging, particularly with MRI, provides a significant benefit to ensure dosimetric coverage of the tumor and avoidance of the nearby OAR (vagina, bladder, rectum, sigmoid, and bowel) (Fig. 1)(2). The traditional use of prescription to point A may underdose tumors with significant residual disease at brachytherapy (2), increasing the risk of a local recurrence. In contrast, in clinical scenarios in which a small residual tumor is present, the tumor dose is typically higher than point A dose and an unnecessarily high exposure of adjacent OAR may ensue.

3D image-based brachytherapy in gynecologic cancers has evolved to include many different types of cancers, applicators and approaches. Centers that have access to an MR scanner available for interventional procedures may choose a real-time approach, with imaging used to properly position the applicator while actively visualizing the tumor (16). The great majority of radiation centers, however, haves an MR unit in the hospital but not necessarily in the radiation oncology department or not equipped for interventional brachytherapy procedures. Therefore the more widely used approach is to obtain an MRI after applicator insertion for contouring and planning purposes. US may be used during the insertion procedure instead of MR to provide real-time visualization for proper placement of the applicator, in particular for avoidance of perforations (17), and MRI obtained before the first brachytherapy application may assist the planning of the implantation as well (18). CT is the most commonly available imaging modality in radiation oncology departments, and the most commonly used worldwide for brachytherapy imaging (19). CT allows for OAR delineation, but CT-based target contouring shows systematically wider contours than with MRI (20). This uncertainty limits the degree of dose optimization possible, in particular in large tumors with parametrial invasion. Therefore, MRI remains the gold standard for delineation of target structures in image-guided brachytherapy.

The importance of performing repeated MRI in brachytherapy depends on tumor size and the timing of brachytherapy (21-23). If brachytherapy starts early, while shrinkage from EBRT is still an essential factor, the use of MRI for each fraction has a higher impact compared to scenarios where brachytherapy is applied towards the end of EBRT (24). Given the availability of CT, one paradigm for limiting the number of MRI scans is to integrate information from MRI to CT by registration of the MRI from the first brachytherapy fraction to subsequent fractions planned on CT (25). Furthermore, MRI performed before the first brachytherapy insertion can be used to assist with contouring on CT, although fusion is not directly feasible due to distortion created by the placement of the applicator. 


\section{Prostate cancer}

The current standard of care for prostate brachytherapy simulation and treatment planning is transrectal ultrasound (TRUS) imaging of the prostate using a TRUS probe. However, there are several advantages to MRI simulation, including superior intra-prostatic localization of the dominant lesion and better anatomic delineation of the apex, base, neurovascular bundles, external urinary sphincter, bladder neck, and intraprostatic ejaculatory ducts (Fig. 3). The rapid ultrasound real-time imaging processing and accessibility of intraoperative ultrasound imaging have limited the role of MRI for prostate brachytherapy simulation. However, as MRI evolves, with greater acceptance for staging of the intraprostatic dominant lesions, and extracapsular extension of disease (26;27), MRI simulation and treatment planning are emerging as active areas of investigation. MRI has been incorporated in the prostate brachytherapy procedure on different levels: real time implantation guidance (27; 28), high-dose-rate (HDR) dose optimization (29) and low-dose-rate (LDR) post-implant dosimetry $(30 ; 31)$.

Real-time MRI guidance has been developed for placement of permanent sources as well as HDR needles into the prostate gland in $0.5 \mathrm{~T}$ and $1.5 \mathrm{~T}$ scanners, respectively $(27 ; 28)$. As an alternative to the MRI real-time approach, which is resource demanding and time consuming, MRI can be acquired after US-guided needle implantation to facilitate improved dose optimization for HDR brachytherapy. This approach can be used for boosting the entire gland or sub-volumes in combination with EBRT, as well as for HDR mono-therapy (29). Furthermore, multi-parametric MRI has emerged as the standard imaging modality to evaluate recurrent disease in men with a rising PSA following prostate-cancer treatment, and has therefore also been explored for MRI-guided salvage brachytherapy (32).

The role of MRI in post-implant LDR assessment is an area of active investigation $(30 ; 31)$ due to the excellent visualization of the prostate gland. MRI-based sector analysis may also refine and enhance quality assurance by facilitating MRI-based dosimetric markers for disease outcome and treatment related morbidity (12). A challenge with MRI-based postimplant dosimetry is that titanium seeds are difficult to localize due to their negative contrast with susceptibility artifacts and are often mistaken for strands, needle tracks, or vessels (33). Therefore MRI fusion with CT can be applied for improved seed localization (34). However, MRI/CT-based postimplant dosimetry outside of the academic setting is not widely used. Current real and perceived barriers include cost, inconvenience for the patient, and suboptimal image fusion registration.

\section{MR imaging}

\section{Anatomic MRI}

GEC ESTRO recommendations on MR imaging (9) in cervix cancer advocate MRI at the time of diagnosis and at brachytherapy with $\mathrm{T} 2 \mathrm{w}$ sequences being the gold standard for the purpose of target definition. Assessment of the target extension in all planes is aided by performing para-transverse, para-coronal and sagittal imaging oriented according to the applicator. Due to relatively long acquisition time, this approach has an inherent risk of motion between each acquisition. Recently, 3D T2w FSE sequences with variable flip angle 
have been introduced for diagnostic imaging of the pelvis and other anatomic regions (35). However, further studies are needed to benchmark it against the gold-standard 2D approach, as the higher isotropic resolution comes at the price of different contrast.

For prostate brachytherapy treatment planning, T2w MRI offers optimal prostate-gland visualization and discrimination between peripheral zone and central gland (36). However, the sensitivity and specificity of T2w MRI for primary tumor identification has limitations in this multifocal disease. MRI with an endorectal coil is currently the standard of care for staging of the prostate and dominant intraprostatic lesions. However, prostate deformation from the endorectal coil induces problems for treatment-planning purposes (37) requiring alternative MR sequences without the endorectal coil (e.g. non-diagnostic axial T2w and/or 3D protocol sequences) (Supplementary Video 1).

\section{Functional imaging}

Intra- and inter-tumor variations such as hypoxia are relevant for radiation response in cervix cancer. Tumor sub-volumes with poor perfusion as imaged with dynamic contrastenhanced (DCE) MRI have been proposed as a surrogate for hypoxia (38). However, it is currently not clear if low-perfusion regions represent radioresistant sub-volumes, and so far DCE MRI has not been incorporated into brachytherapy treatment planning. DWI at the time of cervix brachytherapy has been applied for evaluation of the extent of the residual GTV (39; 40) (Fig. 2).

In prostate cancer, multiparametric MRI using functional imaging such as DWI, DCE and, less frequently, MR spectroscopy is currently being increasingly recognized as a standard in the diagnostic setting (41). Inclusion of functional MRI for prostate brachytherapy can improve the identification of intra-prostatic lesions, which is of particular interest for salvage prostate brachytherapy and for subvolume boosting (42-44).

\section{Brachytherapy applicators and seeds: artifacts and visualization}

Applicators must be MRI-compatible in order to avoid heating and mechanical tissue injuries. Commercial solutions for prostate and gynecologic HDR and pulsed-dose-rate (PDR) brachytherapy include non-metallic (plastic) and titanium applicators. Applicators appear as negative contrast or signal voids in the images. However, MRI-compatible titanium applicators induce susceptibility artifacts which depend on image sequence and which become larger with increasing field strength. Use of intracavitary titanium applicators for cervix brachytherapy is feasible at field strengths of 1.5 and lower. Titanium applicators may also be feasible at 3T with spin-echo sequences (45), but DWI at 3T with titanium is not possible due to significant susceptibility artifacts and geometric distortions.

Reconstruction of brachytherapy applicators and prostate brachytherapy seeds are in general more challenging in MRI as compared with CT because of the lack of contrast of applicators and seeds. Furthermore, metallic distortions lead to signal build-up which may not appear at the exact position of the applicator, leading to potential uncertainties in reconstruction of applicators. Additional MR sequences such as T1W (46), proton-weighted MRI (47), 3D sequences (48) or CT (48) may be applied for improved visualization of applicator and seeds. MRI-based applicator localization is an active area of investigation, and there is 
currently progress in the development of new sequences and reconstruction methods which are specifically adapted to the purpose of seed and applicator visualization (49).

In gynecologic applicators, efforts are being made to exploit markers with contrast from fluids such as $\mathrm{CuSO} 4$, cobalt-cloride, water, or ultrasound gel (46; 50-52). Such positivecontrast substances may be inserted into the source channels of an intracavitary applicator or into well-defined cavities in the applicator, such as holes in the ring or ovoids. Fluid markers should not be applied in needles, because the needle-wall thickness is too thin to generate sufficient contrast towards the fluid. New developments include seed localization MRI markers for prostate brachytherapy, where a cobalt chloride complex contrast agent (C4) is placed adjacent to the implanted seed $(33 ; 53)$ (Fig. 4). These markers are awaiting clinical testing.

\section{Geometry and dose calculation}

The spatial accuracy of MR images is crucial as distortions will directly translate into uncertainties in source location and target/organ delineation. For cervix and prostate brachytherapy, the relevant anatomy and applicator is in the central part of the magnet with high homogeneity of the $\mathrm{B} 0$ field. Patient-related susceptibility-induced distortions are limited for spin-echo sequences ( $<0.8 \mathrm{~mm}$ for gradient strengths $>15 \mathrm{mT} / \mathrm{m}$ at $3 \mathrm{~T}(54)$ ), whereas titanium susceptibility artifacts may compromise image quality and geometric accuracy significantly (see section above on applicators). Furthermore, fast imaging techniques like echo planar imaging (EPI) techniques as used for DWI may induce significant geometric uncertainties.

The lack of Hounsfield units is of specific concern for EBRT dose calculation, but this problem is less pronounced in afterloading brachytherapy using high-energy sources like 192-Ir, 137-Cs, or 60-Co. The heterogeneity corrections originating from the energy dependence of the tissue composition are modest, and the dose calculation can be based on water according to the TG43 algorithm where Hounsfield unit information is not needed (55). Dose-calculation uncertainties are more pronounced with low-energy 125-I and 103-Pd sources for LDR prostate brachytherapy due to the high-density material of the radioactive seeds. Only recently have heterogeneity corrections become available in brachytherapy and the field is currently in a transition period between TG43 and model-based dose-calculation methodologies (56).

\section{MRI-guided treatment planning}

\section{Target definition}

Brachytherapy target definition in cervix cancer relies on an adaptive target concept exploiting repeated imaging and clinical examination before and during radiochemotherapy to individually tailor the brachytherapy boost to the residual tumor. At time of brachytherapy and preferably with the applicator in situ, T2W imaging is used to assess the residual GTV $\left(\mathrm{GTV}_{\text {res }}\right)$, high-risk $\mathrm{CTV}\left(\mathrm{CTV}_{\mathrm{HR}}\right)$ as well as the intermediate-risk CTV $\left(\mathrm{CTV}_{\mathrm{IR}}\right)$ according to the GEC ESTRO recommendations (6) and the upcoming ICRU/GEC ESTRO recommendations. MRI improves the visibility of the target structures as compared to $\mathrm{CT}$, but target contouring still bears a major part of the uncertainties related to the image- 
guided procedure with a mean relative standard deviation of 8-10\% for the GTV and $\mathrm{CTV}_{\mathrm{HR}}(57-59)$.

In prostate cancer, a multi-observer study of MRI prostate definition suggested improvements in anatomic delineation at both the base and apex of the prostate and rectal wall which could reduce rectal and urologic complications. Furthermore, MRI allows for detailed inter-prostatic anatomic information such as external urinary sphincter, dominant lesions, and prostate gland base and apex (Fig. 3).

\section{Dose planning}

GEC-ESTRO recommendations for applicator reconstruction describe the reconstruction procedure on MRI for both intracavitary and interstitial HDR and PDR applicators (8). Recent software tools in treatment-planning systems have improved the identification of rigid intracavitary applicators through application of predefined applicator geometries including the source path (60). The source path geometry should be taken from the date from commissioning, combined with landmarks at the applicators, which can be made visible either via the applicator shape alone or special MRI markers. In recent seed reconstruction investigations, CT- based reconstruction remained superior to T1-based seed reconstruction due to manual interpretation of the seed signal voids, although MRI/CT fusion uncertainties may considerably diminish the advantage of using CT-based reconstruction in MRI-based planning (61).

Image registration is the combination of several image sequences/modalities from one time point and/or sequential images from several time points. Image registration is applied for reconstruction of applicators (8), propagation of brachytherapy target contours across image modalities or across different time points (25), or for dose accumulation (62). Intra- and inter-fraction movements of the tumor relative to the applicator is limited in cervix intracavitary applications (57), and therefore registration between image series should always be performed in reference to the applicator, and registration on bone is strongly discouraged. For interstitial implants there may be systematic movements of the needles relative to the CTV (63), and registration should be based on soft tissue, e.g., the prostate and urethra. The application of deformable registration in MRI guided brachytherapy remains unclear. Deformable registration in bladder and likely also rectum seems to have little advantage for dose accumulation (62), and may even introduce uncertainties due to unreliable deformations. For sigmoid and bowel, dose accumulation based on rigid registration has significant limitations (64), but there exists currently no convincing deformable registration tool for these organs.

The ability to optimize dose distribution to target volumes and a set of OAR contours has changed clinical dose planning practice substantially in gynecologic brachytherapy (2). For smaller tumors there is a trend toward dose de-escalation in order to spare the OAR, whereas for larger tumors with a bad response after EBRT and involvement in the parametria the dose is usually increased. With the improved visualization achieved with MRI, it has also become possible to optimize the applicator geometry by using adapted applicator types or via combination with interstitial applicators $(3 ; 65)$. 
For prostate cancer, MRI-based treatment planning for HDR and LDR treatment of the entire prostate gland is similar to US-based planning, however with the advantage that improved visualization of the gland improves the confidence in dosimetric parameters which are used to assess the quality of the plan (37). Citrin et al. investigated the role of inverse treatment planning for HDR prostate brachytherapy and concluded that application of a set of planning dose constraints reduced uncertainties in MRI treatment planning (66).

The 3D image-guided brachytherapy dose optimization process has resulted in new standards for use of the term prescription. Whereas EBRT and 2D based brachytherapy is often based on dose normalization, image-guided brachytherapy with individualized dose optimization typically does not involve normalization. Usually there is a planning aim, a set of dose constraints for the target volumes and the OAR, which is defined for the patient before brachytherapy. However, the final prescribed dose to the target and OARs depends on the tumor and OAR topography, and DVH parameters for an approved plan are usually different from the initial planning aim.

\section{Clinical outcome of MRI guided brachytherapy}

\section{Cervix cancer}

Clinical outcome for MRI-guided brachytherapy in cervix cancer has been reported by several institutions $(4 ; 5 ; 67-69)$. Currently, the largest available series are those reported from Vienna (156 patients) and Aarhus (140 patients) $(4 ; 5)$, with patients treated within prospective clinical protocols by definitive 3D EBRT, concomitant chemotherapy, and MRIguided brachytherapy according to GEC ESTRO recommendations. The overall actuarial local control rates at 3 years were $95 \%$ and $91 \%$ in the Vienna and Aarhus series, respectively, and according to stage were $100 \%$ for IB, $96 \%$ for IIB and $86 \%$ for IIIB in the Vienna series. Comparisons with historical controls from each institution showed that improved local control translated into a significant improvement in overall survival by $30 \%$ (from $28 \%$ to $68 \%$ ) and $16 \%$ (from $63 \%$ to $79 \%$ ), respectively $(1 ; 5)$ ). Both series also demonstrated a significant reduction in morbidity as compared to the historical controls. . The use of concomitant chemotherapy as well as more advanced detection and treatment of positive lymph nodes have likely contributed to the improved survival, but given the magnitude of the improvement, the change from standard 2D-based brachytherapy to MRIguided adaptive brachytherapy is thought to have impact on survival. The major improvement in local control was seen in large tumors (stage IIIB), where significant tumor dose escalations of $>10 \mathrm{~Gy}$ had been applied $(1 ; 2)$, in particular through the use of needles in patients with significant residual disease at the time of brachytherapy.

The use of MRI guidance has also demonstrated excellent results in vaginal cancer as well as in recurrent gynecologic cancer treated with interstitial brachytherapy $(16 ; 70 ; 71)$. With the use of mean high total doses $>80 \mathrm{~Gy}$, it has been demonstrated that high levels of local control of $>90 \%$ can be been obtained $(70 ; 71)$.

\section{Prostate cancer}

The major advantage of using MRI for whole-gland LDR and HDR treatment as compared to US and CT based approaches is to reduce uncertainties and improve quality. Currently, 
the addition of MRI has not resulted in significant changes to clinical practice and dose administration, however, dose differentiation and OAR avoidance (i.e. urinary sphincters and rectum) has the potential to measurably impact future clinical outcomes. Improved precision of contouring and dose assessment is the prerequisite for improved assessment of the dose effect relationships for OARs such as e.g. the urinary sphincter (14). Significant dose discrepancies have been found with CT- as compared to MRI-based sector analysis (12), and the next step is to utilize the improved target-dose assessment to improve outcome prediction.

Several investigators have considered partial treatment of the prostate gland based on intraprostatic MRI information. Specifically, Ares et al. focused the boost radiation delivery to the peripheral zone of the prostate in a dose-escalation study of 77 patients treated with an MRI-guided HDR boost. The 3-year biochemical disease-free survival and disease-specific survival rates were $87 \%$ and $100 \%$, respectively (72). Partial volume with monotherapy was investigated in a study with 318 patients which demonstrated less than optimal PSA failurefree survival outcomes for favorable intermediate-risk patients $(73.0 \%$ at 5 years and $66.4 \%$ at 8 years) (32). D'Amico et al. reported that the 5-year PSA control was 95\% in 196 patients with cT1c, PSA $<10 \mathrm{ng} / \mathrm{ml}$, and biopsy Gleason score $3+4$ or less without perineural invasion treated to the peripheral zone (73). An update report on MRI-guided partial prostate brachytherapy by Nguyen et al. included 318 men with PSA $<15 \mathrm{ng} / \mathrm{ml}$, cT1c, and Gleason score $3+4$ or less and showed 8-year PSA failure-free survival rates for low- and intermediate-risk disease of $80.4 \%$ and $66.4 \%$, respectively (32).

In a prospective phase II study of MRI-guided salvage brachytherapy following EBRT recurrences for men with favorable-risk prostate cancer, Nguyen et al. reported a PSA control rate of $70 \%$ at 4 years and grade 3 or 4 GI or GU toxicity of $30 \%$. It is important to note that $13 \%$ required a colostomy and/or urostomy to repair a fistula (74).

\section{Future perspectives}

Obtaining further evidence for the significant clinical benefit of MRI-guided brachytherapy in cervix cancer is the key to moving forward with further dissemination of the technique. In 2008, the GEC-ESTRO Gyn network initiated the "International Study on MRI-Based Brachytherapy in Cervical Cancer" (EMBRACE, www.embracestudy.dk). EMBRACE has recruited >1000 patients by 2013 from 30 international centers performing MRI-guided brachytherapy. The purpose of the EMBRACE study is to evaluate and benchmark MRIguided brachytherapy in a prospective multicenter study. In 2010, the GEC-ESTRO group also initiated the retrospective study retroEMBRACE, in which $>800$ patients treated with image-guided brachytherapy prior to EMBRACE accrual have been included to provide long-term outcome data for image-guided brachytherapy while the EMBRACE study data is still maturing (www.retroembrace.com).

MRI-guided brachytherapy in cervix cancer is an advanced technique which relies on new applications of imaging, target concepts, and dose planning principles and the utilization of new applicators. The implementation of high quality treatment requires a multidisciplinary team, and appropriate expertise can only be obtained and maintained with a certain patient 
load, such as e.g. $>10-15$ patients per year. Recent studies show that the most important source of uncertainty to address in the image-guided procedure is target delineation (24; 5759) which underlines the necessity of training and expertise as well as quality assurance in clinical studies. A recent paper reports on a concerning decrease in the utilization of brachytherapy in the U.S. (75). Brachytherapy was reported in only $63 \%$ of patients between 1988 and 2009, and there was a decline after year 2000. The clinical outcome was significantly worse in patients treated with EBRT alone. Promotion of high quality treatment for cervix cancer is clearly needed.

During the last decades, EBRT dose escalation has been demonstrated to be associated with improved progression-free survival in prostate cancer. There are also indications that IMRT (50.4 Gy) combined with HDR boost (21 Gy in 3 fractions) is associated with superior PSArelapse-free survival compared to high-dose IMRT ( $86.4 \mathrm{~Gy})$; this is likely related to the higher prostate dose by adding the brachytherapy boost (76). As local recurrences occur mainly at the site of the primary lesions as the example shown in the Fig. 5a next logical step is to consider whether inhomogeneous dose distributions, according to risk of recurrence, may improve the balance between side effects and tumor control. Differential dose distributions with focal boosting of primary lesions combined with whole-gland irradiation is addressed in the ongoing randomized phase III FLAME trial (http:// clinicaltrials.gov/ct2/show/NCT01168479) where integrated IMRT boosting to $95 \mathrm{~Gy}$ is used to escalate the dose to the primary lesion in the experimental arm. Given that the FLAME trial shows improved outcome with focal boosting, it is attractive to consider MRIguided brachytherapy for the boost for a potential improved balance between OAR and tumor dose. Further improvements in OAR sparing may even be possible by considering the option to combine the dose escalation to primary lesions with dose de-escalation to the parts of the prostate where macroscopic lesions are not visible. Such an approach would reflect the differential risk of recurrence by discriminating between tissue at risk of microscopic spread or with very small lesions and tissue with a high macroscopic tumor load.

A current limitation on the spread of MRI-guided brachytherapy in both prostate and cervix cancer into wide clinical practice is the problem of access to MRI and the increased costs of additional imaging. Strategies to adapt the amount of extra imaging according to the possibilities in departments with different resources is crucial for the dissemination of MRIguided brachytherapy. As discussed above, such scenarios in gynecologic brachytherapy may include MRI without the applicator in place combined with CT, or MRI for the first brachytherapy fraction combined with $\mathrm{CT}$ for succeeding fractions. In prostate brachytherapy, MRI combined with CT is currently used to improve reconstruction accuracy. However, improved visualization of seeds and applicators can make it possible to omit CT scans to reduce the load of imaging to the patient and to the department.

New avenues for advanced dose assessment in OARs can also be exploited with MRIguided cervix and prostate brachytherapy. Gastrointestinal and genitourinary morbidity as well as side effects related to sexual function should be investigated prospectively with validated instruments. Further refined identification of OARs and subvolumes related to endpoints of relevance to patient quality of life are of significant interest. 
MRI-guided adaptive radiotherapy as applied in cervix cancer has significant potential for application in other disease sites. Sites of specific relevance are those which exhibit significant and individual response during radiotherapy, and where a focal boost has potential to decrease the incidence of local failure and/or to limit the irradiated volume so as to decrease morbidity. Examples of such sites are other gynecologic indications, rectum, anal canal, lung, and head and neck cancer. Current protocols on EBRT dose escalation in NSCLC (77) and head and neck cancer (78) are aiming for dose escalation using advanced imaging and treatment to improve local control.

\section{Conclusion}

Mono-institutional reports indicate that individualized, adaptive, MRI-guided brachytherapy improves the clinical outcome in cervix-cancer patients. Future efforts in cervix cancer should be directed toward dissemination of MRI guidance through focused training and establishment of high quality treatment in centers with multidisciplinary expertise and sufficient patient load. MRI-guided prostate brachytherapy has improved the visibility and accuracy of dose administration. Utilization of MRI in prostate cancer has the potential to improve clinical outcome by allowing better identification of primary lesions and the administration of dose according to the risk of recurrence.

\section{Supplementary Material}

Refer to Web version on PubMed Central for supplementary material.

\section{Acknowledgments}

Aarhus University Hospital was supported by research grants from the Danish Cancer Society, Danish Council for Strategic Research, CIRRO-the Lundbeck Foundation Centre for Interventional Research in Radiation Oncology. Funding from the European Programme (FP7/2013-2016) under grant agreement ICT-2011.5.2 (DrTherapat) was received. The work of Christian Kirisits was supported by the Austrian Science Fund FWF grant No L562. The work of Akila Viswanatan was supported by the grant R21 NIH CA167800. The work of Steven J. Frank was supported by the grant NIH/NCI-R43. Tharakeswara K. Bathala, MD Anderson Cancer Center, is acknowledged for support with prostate MRI figures.

Conflicts of interest: The GEC ESTRO gyn network coordinated by Medical University of Vienna and Aarhus University Hospital has received research grants from Varian Medical Systems, Nucletron - an Elekta Company, and Bebig for coordination of research and for conduction of the EMBRACE trial. Aarhus University Hospital receives financial support for educational purposes from Varian Medical Systems. The Department of Radiotherapy at Medical University of Vienna receives financial and/or equipment support for research and educational purposes from Nucletron, an Elekta company and Varian Medical Systems, Inc. Christian Kirisits is a consultant to Nucletron, an Elekta company. Dr Viswanathan has received an honorarium from Nucletron. Steven J. Frank is founder and director of C4 Imaging and has received an honorarium from Biocompatibles [BTG].

\section{Reference List}

1. Pötter R, Dimopoulos J, Georg P, Lang S, Waldhausl C, Wachter-Gerstner N, et al. Clinical impact of MRI assisted dose volume adaptation and dose escalation in brachytherapy of locally advanced cervix cancer. Radiother Oncol. 2007 May; 83(2):148-155. [PubMed: 17531904]

2. Tanderup K, Nielsen SK, Nyvang GB, Pedersen EM, Rohl L, Aagaard T, et al. From point A to the sculpted pear: MR image guidance significantly improves tumour dose and sparing of organs at risk in brachytherapy of cervical cancer. Radiother Oncol. 2010 Feb; 94(2):173-180. [PubMed: 20138380] 
3. Jürgenliemk-Schulz IM, Tersteeg RJ, Roesink JM, Bijmolt S, Nomden CN, Moerland MA, et al. MRI-guided treatment-planning optimisation in intracavitary or combined intracavitary/interstitial PDR brachytherapy using tandem ovoid applicators in locally advanced cervical cancer. Radiother Oncol. 2009 Nov; 93(2):322-330. [PubMed: 19748695]

4. Pötter R, Georg P, Dimopoulos JC, Grimm M, Berger D, Nesvacil N, et al. Clinical outcome of protocol based image (MRI) guided adaptive brachytherapy combined with 3D conformal radiotherapy with or without chemotherapy in patients with locally advanced cervical cancer. Radiother Oncol. 2011 Jul; 100(1):116-123. [PubMed: 21821305]

5. Lindegaard JC, Fokdal LU, Nielsen SK, Juul-Christensen J, Tanderup K. MRI-guided adaptive radiotherapy in locally advanced cervical cancer from a Nordic perspective. Acta Oncol. 2013 Oct; 52(7):1510-1519. [PubMed: 23962242]

6. Haie-Meder C, Pötter R, van LE, Briot E, de Brabandere M, Dimopoulos J, et al. Recommendations from Gynaecological (GYN) GEC-ESTRO Working Group (I): concepts and terms in 3D image based 3D treatment planning in cervix cancer brachytherapy with emphasis on MRI assessment of GTV and CTV. Radiother Oncol. 2005 Mar; 74(3):235-245. [PubMed: 15763303]

7. Pötter R, Haie-Meder C, van LE, Barillot I, De BM, Dimopoulos J, et al. Recommendations from gynaecological (GYN) GEC ESTRO working group (II): concepts and terms in 3D image-based treatment planning in cervix cancer brachytherapy-3D dose volume parameters and aspects of 3D image-based anatomy, radiation physics, radiobiology. Radiother Oncol. 2006 Jan; 78(1):67-77. [PubMed: 16403584]

8. Hellebust TP, Kirisits C, Berger D, Perez-Calatayud J, De BM, De LA, et al. Recommendations from Gynaecological (GYN) GEC-ESTRO Working Group: considerations and pitfalls in commissioning and applicator reconstruction in 3D image-based treatment planning of cervix cancer brachytherapy. Radiother Oncol. 2010 Aug; 96(2):153-160. [PubMed: 20663578]

9. Dimopoulos JC, Petrow P, Tanderup K, Petric P, Berger D, Kirisits C, et al. Recommendations from Gynaecological (GYN) GEC-ESTRO Working Group (IV): Basic principles and parameters for MR imaging within the frame of image based adaptive cervix cancer brachytherapy. Radiother Oncol. 2012 Apr; 103(1):113-122. [PubMed: 22296748]

10. Viswanathan AN, Beriwal S, De Los Santos JF, Demanes DJ, Gaffney D, Hansen J, et al. American Brachytherapy Society consensus guidelines for locally advanced carcinoma of the cervix. Part II: high-dose-rate brachytherapy. Brachytherapy. 2012 Jan; 11(1):47-52. [PubMed: 22265437]

11. Viswanathan AN, Thomadsen B. American Brachytherapy Society consensus guidelines for locally advanced carcinoma of the cervix. Part I: general principles. Brachytherapy. 2012 Jan; 11(1):33-46. [PubMed: 22265436]

12. Takiar V, Pugh TJ, Swanson D, Kudchadker RJ, Bruno TL, McAvoy S, et al. MRI-based sector analysis enhances prostate palladium-103 brachytherapy quality assurance in a phase II prospective trial of men with intermediate-risk localized prostate cancer. Brachytherapy. 2013 May 11.

13. McLaughlin PW, Troyer S, Berri S, Narayana V, Meirowitz A, Roberson PL, et al. Functional anatomy of the prostate: implications for treatment planning. Int J Radiat Oncol Biol Phys. 2005 Oct 1; 63(2):479-491. [PubMed: 16168840]

14. Register SP, Kudchadker RJ, Levy LB, Swanson DA, Pugh TJ, Bruno TL, et al. An MRI-based dose--reponse analysis of urinary sphincter dose and urinary morbidity after brachytherapy for prostate cancer in a phase II prospective trial. Brachytherapy. 2013 May; 12(3):210-216. [PubMed: 23466360]

15. Wang JZ, Mayr NA, Zhang D, Li K, Grecula JC, Montebello JF, et al. Sequential magnetic resonance imaging of cervical cancer: the predictive value of absolute tumor volume and regression ratio measured before, during, and after radiation therapy. Cancer. 2010 Nov 1; 116(21):5093-5101. [PubMed: 20629080]

16. Viswanathan AN, Szymonifka J, Tempany-Afdhal CM, O'Farrell DA, Cormack RA. A prospective trial of real-time magnetic resonance-guided catheter placement in interstitial gynecologic brachytherapy. Brachytherapy. 2013 May; 12(3):240-247. [PubMed: 23415048] 
17. Davidson MT, Yuen J, D'Souza DP, Radwan JS, Hammond JA, Batchelar DL. Optimization of high-dose-rate cervix brachytherapy applicator placement: the benefits of intraoperative ultrasound guidance. Brachytherapy. 2008 Jul; 7(3):248-253. [PubMed: 18635025]

18. Fokdal L, Tanderup K, Hokland SB, Rohl L, Pedersen EM, Nielsen SK, et al. Clinical feasibility of combined intracavitary/interstitial brachytherapy in locally advanced cervical cancer employing MRI with a tandem/ring applicator in situ and virtual preplanning of the interstitial component. Radiother Oncol. 2013 Apr; 107(1):63-68. [PubMed: 23452917]

19. Viswanathan AN, Creutzberg CL, Craighead P, McCormack M, Toita T, Narayan K, et al. International brachytherapy practice patterns: a survey of the Gynecologic Cancer Intergroup (GCIG). Int J Radiat Oncol Biol Phys. 2012 Jan 1; 82(1):250-255. [PubMed: 21183288]

20. Viswanathan AN, Dimopoulos J, Kirisits C, Berger D, Pötter R. Computed tomography versus magnetic resonance imaging-based contouring in cervical cancer brachytherapy: results of a prospective trial and preliminary guidelines for standardized contours. Int J Radiat Oncol Biol Phys. 2007 Jun 1; 68(2):491-498. [PubMed: 17331668]

21. Mohamed S, Nielsen SK, Fokdal LU, Pedersen EM, Lindegaard JC, Tanderup K. Feasibility of applying a single treatment plan for both fractions in PDR image guided brachytherapy in cervix cancer. Radiother Oncol. 2013 Apr; 107(1):32-38. [PubMed: 23333020]

22. Kirisits C, Lang S, Dimopoulos J, Oechs K, Georg D, Pötter R. Uncertainties when using only one MRI-based treatment plan for subsequent high-dose-rate tandem and ring applications in brachytherapy of cervix cancer. Radiother Oncol. 2006 Dec; 81(3):269-275. [PubMed: 17126938]

23. Lang S, Nesvacil N, Kirisits C, Georg P, Dimopoulos JC, Federico M, et al. Uncertainty analysis for 3D image-based cervix cancer brachytherapy by repetitive MR imaging: assessment of DVHvariations between two HDR fractions within one applicator insertion and their clinical relevance. Radiother Oncol. 2013 Apr; 107(1):26-31. [PubMed: 23541645]

24. Nesvacil N, Tanderup K, Hellebust TP, De LA, Lang S, Mohamed S, et al. A multicentre comparison of the dosimetric impact of inter- and intra-fractional anatomical variations in fractionated cervix cancer brachytherapy. Radiother Oncol. 2013 Apr; 107(1):20-25. [PubMed: 23602372]

25. Nesvacil N, Pötter R, Sturdza A, Hegazy N, Federico M, Kirisits C. Adaptive image guided brachytherapy for cervical cancer: a combined MRI-/CT-planning technique with MRI only at first fraction. Radiother Oncol. 2013 Apr; 107(1):75-81. [PubMed: 23068712]

26. Haider MA, van der Kwast TH, Tanguay J, Evans AJ, Hashmi AT, Lockwood G, et al. Combined T2-weighted and diffusion-weighted MRI for localization of prostate cancer. AJR Am J Roentgenol. 2007 Aug; 189(2):323-328. [PubMed: 17646457]

27. D'Amico AV, Cormack R, Tempany CM, Kumar S, Topulos G, Kooy HM, et al. Real-time magnetic resonance image-guided interstitial brachytherapy in the treatment of select patients with clinically localized prostate cancer. Int J Radiat Oncol Biol Phys. 1998 Oct 1; 42(3):507-515. [PubMed: 9806508]

28. Menard C, Susil RC, Choyke P, Gustafson GS, Kammerer W, Ning H, et al. MRI-guided HDR prostate brachytherapy in standard 1.5T scanner. Int J Radiat Oncol Biol Phys. 2004 Aug 1; 59(5): 1414-1423. [PubMed: 15275727]

29. Hoskin PJ, Colombo A, Henry A, Niehoff P, Hellebust TP, Siebert FA, et al. GEC/ESTRO recommendations on high dose rate afterloading brachytherapy for localised prostate cancer: An update. Radiother Oncol. 2013 Jun; 107(3):325-332. [PubMed: 23773409]

30. Moerland MA, Wijrdeman HK, Beersma R, Bakker CJ, Battermann JJ. Evaluation of permanent I-125 prostate implants using radiography and magnetic resonance imaging. Int J Radiat Oncol Biol Phys. 1997 Mar 1; 37(4):927-933. [PubMed: 9128971]

31. Ohashi T, Momma T, Yamashita S, Nagatsuma K, Kanai K, Kitagawa K, et al. Impact of MRIbased postimplant dosimetric assessment in prostate brachytherapy using contrast-enhanced T1weighted images. Brachytherapy. 2012 Nov; 11(6):468-475. [PubMed: 22330102]

32. Nguyen PL, Chen MH, Zhang Y, Tempany CM, Cormack RA, Beard CJ, et al. Updated results of magnetic resonance imaging guided partial prostate brachytherapy for favorable risk prostate cancer: implications for focal therapy. J Urol. 2012 Oct; 188(4):1151-1156. [PubMed: 22901567] 
33. Frank SJ, Stafford RJ, Bankson JA, Li C, Swanson DA, Kudchadker RJ, et al. A novel MRI marker for prostate brachytherapy. Int J Radiat Oncol Biol Phys. 2008 May 1; 71(1):5-8. [PubMed: 18406882]

34. Polo A, Cattani F, Vavassori A, Origgi D, Villa G, Marsiglia H, et al. MR and CT image fusion for postimplant analysis in permanent prostate seed implants. Int J Radiat Oncol Biol Phys. 2004 Dec 1; 60(5):1572-1579. [PubMed: 15590189]

35. Lichy MP, Wietek BM, Mugler JP, Horger W, Menzel MI, Anastasiadis A, et al. Magnetic resonance imaging of the body trunk using a single-slab, 3-dimensional, T2-weighted turbo-spinecho sequence with high sampling efficiency (SPACE) for high spatial resolution imaging: initial clinical experiences. Invest Radiol. 2005 Dec; 40(12):754-760. [PubMed: 16304477]

36. Pugh TJ, Frank SJ, Achim M, Kuban DA, Lee AK, Hoffman KE, et al. Endorectal magnetic resonance imaging for predicting pathologic T3 disease in Gleason score 7 prostate cancer: implications for prostate brachytherapy. Brachytherapy. 2013 May; 12(3):204-209. [PubMed: 22673704]

37. Albert JM, Swanson DA, Pugh TJ, Zhang M, Bruno TL, Kudchadker RJ, et al. Magnetic resonance imaging-based treatment planning for prostate brachytherapy. Brachytherapy. 2013 Jan; 12(1):3037. [PubMed: 22727474]

38. Halle C, Andersen E, Lando M, Aarnes EK, Hasvold G, Holden M, et al. Hypoxia-induced gene expression in chemoradioresistant cervical cancer revealed by dynamic contrast-enhanced MRI. Cancer Res. 2012 Oct 15; 72(20):5285-5295. [PubMed: 22890239]

39. Haack S, Pedersen EM, Jespersen SN, Kallehauge JF, Lindegaard JC, Tanderup K. Apparent diffusion coefficients in GEC ESTRO target volumes for image guided adaptive brachytherapy of locally advanced cervical cancer. Acta Oncol. 2010 Oct; 49(7):978-983. [PubMed: 20831485]

40. Esthappan J, Ma DJ, Narra VR, Raptis CA, Grigsby PW. Comparison of apparent diffusion coefficient maps to T2-weighted images for target delineation in cervix cancer brachytherapy. $\mathrm{J}$ Contemp Brachytherapy. 2011 Dec; 3(4):193-198. [PubMed: 23346128]

41. Barentsz JO, Richenberg J, Clements R, Choyke P, Verma S, Villeirs G, et al. ESUR prostate MR guidelines 2012. Eur Radiol. 2012 Apr; 22(4):746-757. [PubMed: 22322308]

42. Bauman G, Haider M, Van der Heide UA, Menard C. Boosting imaging defined dominant prostatic tumors: A systematic review. Radiother Oncol. 2013 Jun; 107(3):274-281. [PubMed: 23791306]

43. Haider MA, Chung P, Sweet J, Toi A, Jhaveri K, Menard C, et al. Dynamic contrast-enhanced magnetic resonance imaging for localization of recurrent prostate cancer after external beam radiotherapy. Int J Radiat Oncol Biol Phys. 2008 Feb 1; 70(2):425-430. [PubMed: 17881141]

44. Groenendaal G, Borren A, Moman MR, Monninkhof E, van Diest PJ, Philippens ME, et al. Pathologic validation of a model based on diffusion-weighted imaging and dynamic contrastenhanced magnetic resonance imaging for tumor delineation in the prostate peripheral zone. Int $\mathrm{J}$ Radiat Oncol Biol Phys. 2012 Mar 1; 82(3):e537-e544. [PubMed: 22197085]

45. Kim Y, Muruganandham M, Modrick JM, Bayouth JE. Evaluation of artifacts and distortions of titanium applicators on 3.0-Tesla MRI: feasibility of titanium applicators in MRI-guided brachytherapy for gynecological cancer. Int J Radiat Oncol Biol Phys. 2011 Jul 1; 80(3):947-955. [PubMed: 20934275]

46. Haack S, Nielsen SK, Lindegaard JC, Gelineck J, Tanderup K. Applicator reconstruction in MRI 3D image-based dose planning of brachytherapy for cervical cancer. Radiother Oncol. 2009 May; 91(2):187-193. [PubMed: 18977049]

47. Hu Y, Esthappan J, Mutic S, Richardson S, Gay HA, Schwarz JK, et al. Improve definition of titanium tandems in MR-guided high dose rate brachytherapy for cervical cancer using proton density weighted MRI. Radiat Oncol. 2013; 8:16. [PubMed: 23327682]

48. Kapur T, Egger J, Damato A, Schmidt EJ, Viswanathan AN. 3-T MR-guided brachytherapy for gynecologic malignancies. Magn Reson Imaging. 2012 Nov; 30(9):1279-1290. [PubMed: 22898699]

49. de Leeuw H, Seevinck PR, Bakker CJ. Center-out radial sampling with off-resonant reconstruction for efficient and accurate localization of punctate and elongated paramagnetic structures. Magn Reson Med. 2013 Jun; 69(6):1611-1622. [PubMed: 22847732] 
50. Schindel J, Muruganandham M, Pigge FC, Anderson J, Kim Y. Magnetic resonance imaging (MRI) markers for MRI-guided high-dose-rate brachytherapy: novel marker-flange for cervical cancer and marker catheters for prostate cancer. Int J Radiat Oncol Biol Phys. 2013 Jun 1; 86(2): 387-393. [PubMed: 23433797]

51. Wills R, Lowe G, Inchley D, Anderson C, Beenstock V, Hoskin P. Applicator reconstruction for HDR cervix treatment planning using images from $0.35 \mathrm{~T}$ open MR scanner. Radiother Oncol. 2010 Mar; 94(3):346-352. [PubMed: 19931929]

52. Perez-Calatayud J, Kuipers F, Ballester F, Granero D, Richart J, Rodriguez S, et al. Exclusive MRI-based tandem and colpostats reconstruction in gynaecological brachytherapy treatment planning. Radiother Oncol. 2009 May; 91(2):181-186. [PubMed: 18947893]

53. Frank SJ, Tailor RC, Kudchadker RJ, Martirosyan KS, Stafford RJ, Elliott AM, et al. Anisotropy characterization of I-125 seed with attached encapsulated cobalt chloride complex contrast agent markers for MRI-based prostate brachytherapy. Med Dosim. 2011; 36(2):200-205. [PubMed: 20537886]

54. Stanescu T, Wachowicz K, Jaffray DA. Characterization of tissue magnetic susceptibility-induced distortions for MRIgRT. Med Phys. 2012 Dec; 39(12):7185-7193. [PubMed: 23231269]

55. Nath R, Anderson LL, Luxton G, Weaver KA, Williamson JF, Meigooni AS. Dosimetry of interstitial brachytherapy sources: recommendations of the AAPM Radiation Therapy Committee Task Group No. 43. American Association of Physicists in Medicine. Med Phys. 1995 Feb; 22(2): 209-234. [PubMed: 7565352]

56. Beaulieu L, Carlsson TA, Carrier JF, Davis SD, Mourtada F, Rivard MJ, et al. Report of the Task Group 186 on model-based dose calculation methods in brachytherapy beyond the TG-43 formalism: current status and recommendations for clinical implementation. Med Phys. 2012 Oct; 39(10):6208-6236. [PubMed: 23039658]

57. Tanderup K, Nesvacil N, Potter R, Kirisits C. Uncertainties in image guided adaptive cervix cancer brachytherapy: impact on planning and prescription. Radiother Oncol. 2013 Apr; 107(1):1-5. [PubMed: 23541642]

58. Hellebust TP, Tanderup K, Lervag C, Fidarova E, Berger D, Malinen E, et al. Dosimetric impact of interobserver variability in MRI-based delineation for cervical cancer brachytherapy. Radiother Oncol. 2013 Apr; 107(1):13-19. [PubMed: 23462706]

59. Petric P, Hudej R, Rogelj P, Blas M, Tanderup K, Fidarova E, et al. Uncertainties of target volume delineation in MRI guided adaptive brachytherapy of cervix cancer: a multi-institutional study. Radiother Oncol. 2013 Apr; 107(1):6-12. [PubMed: 23453539]

60. Berger D, Dimopoulos J, Pötter R, Kirisits C. Direct reconstruction of the Vienna applicator on MR images. Radiother Oncol. 2009 Nov; 93(2):347-351. [PubMed: 19625096]

61. de Brabandere M, Hoskin P, Haustermans K, Van den Heuvel F, Siebert FA. Prostate post-implant dosimetry: interobserver variability in seed localisation, contouring and fusion. Radiother Oncol. 2012 Aug; 104(2):192-198. [PubMed: 22857857]

62. Andersen ES, Noe KO, Sorensen TS, Nielsen SK, Fokdal L, Paludan M, et al. Simple DVH parameter addition as compared to deformable registration for bladder dose accumulation in cervix cancer brachytherapy. Radiother Oncol. 2013 Apr; 107(1):52-57. [PubMed: 23490266]

63. Simnor T, Li S, Lowe G, Ostler P, Bryant L, Chapman C, et al. Justification for inter-fraction correction of catheter movement in fractionated high dose-rate brachytherapy treatment of prostate cancer. Radiother Oncol. 2009 Nov; 93(2):253-258. [PubMed: 19854524]

64. Jamema SV, Mahantshetty U, Tanderup K, Malvankar D, Sharma S, Engineer R, et al. Interapplication variation of dose and spatial location of $\mathrm{D}(2 \mathrm{~cm}(3))$ volumes of OARs during MR image based cervix brachytherapy. Radiother Oncol. 2013 Apr; 107(1):58-62. [PubMed: 23453543]

65. Dimopoulos JC, Kirisits C, Petric P, Georg P, Lang S, Berger D, et al. The Vienna applicator for combined intracavitary and interstitial brachytherapy of cervical cancer: clinical feasibility and preliminary results. Int J Radiat Oncol Biol Phys. 2006 Sep 1; 66(1):83-90. [PubMed: 16839702]

66. Citrin D, Ning H, Guion P, Li G, Susil RC, Miller RW, et al. Inverse treatment planning based on MRI for HDR prostate brachytherapy. Int J Radiat Oncol Biol Phys. 2005 Mar 15; 61(4):12671275. [PubMed: 15752909] 
67. Nomden CN, de Leeuw AA, Roesink JM, Tersteeg RJ, Moerland MA, Witteveen PO, et al. Clinical outcome and dosimetric parameters of chemo-radiation including MRI guided adaptive brachytherapy with tandem-ovoid applicators for cervical cancer patients: a single institution experience. Radiother Oncol. 2013 Apr; 107(1):69-74. [PubMed: 23639580]

68. Mahantshetty U, Swamidas J, Khanna N, Engineer R, Merchant NH, Shrivastava S. Magnetic resonance image-based dose volume parameters and clinical outcome with high dose rate brachytherapy in cervical cancers--a validation of GYN GEC-ESTRO brachytherapy recommendations. Clin Oncol (R Coll Radiol ). 2011 Jun; 23(5):376-377. [PubMed: 21377847]

69. Chargari C, Magne N, Dumas I, Messai T, Vicenzi L, Gillion N, et al. Physics contributions and clinical outcome with 3D-MRI-based pulsed-dose-rate intracavitary brachytherapy in cervical cancer patients. Int J Radiat Oncol Biol Phys. 2009 May 1; 74(1):133-139. [PubMed: 18774656]

70. Dimopoulos JC, Schmid MP, Fidarova E, Berger D, Kirisits C, Pötter R. Treatment of locally advanced vaginal cancer with radiochemotherapy and magnetic resonance image-guided adaptive brachytherapy: dose-volume parameters and first clinical results. Int J Radiat Oncol Biol Phys. 2012 Apr 1; 82(5):1880-1888. [PubMed: 21868174]

71. Fokdal L, Tanderup K, Nielsen SK, Christensen HK, Rohl L, Pedersen EM, et al. Image and laparoscopic guided interstitial brachytherapy for locally advanced primary or recurrent gynaecological cancer using the adaptive GEC ESTRO target concept. Radiother Oncol. 2011 Sep; 100(3):473-479. [PubMed: 21924784]

72. Ares C, Popowski Y, Pampallona S, Nouet P, Dipasquale G, Bieri S, et al. Hypofractionated boost with high-dose-rate brachytherapy and open magnetic resonance imaging-guided implants for locally aggressive prostate cancer: a sequential dose-escalation pilot study. Int J Radiat Oncol Biol Phys. 2009 Nov 1; 75(3):656-663. [PubMed: 19250768]

73. D'Amico AV, Tempany CM, Schultz D, Cormack RA, Hurwitz M, Beard C, et al. Comparing PSA outcome after radical prostatectomy or magnetic resonance imaging-guided partial prostatic irradiation in select patients with clinically localized adenocarcinoma of the prostate. Urology. 2003 Dec; 62(6):1063-1067. [PubMed: 14665356]

74. Nguyen PL, Chen RC, Clark JA, Cormack RA, Loffredo M, McMahon E, et al. Patient-reported quality of life after salvage brachytherapy for radio-recurrent prostate cancer: A prospective Phase II study. Brachytherapy. 2009 Oct; 8(4):345-352. [PubMed: 19428311]

75. Han K, Milosevic M, Fyles A, Pintilie M, Viswanathan AN. Trends in the utilization of brachytherapy in cervical cancer in the United States. Int J Radiat Oncol Biol Phys. 2013 Sep 1; 87(1):111-119. [PubMed: 23849695]

76. Deutsch I, Zelefsky MJ, Zhang Z, Mo Q, Zaider M, Cohen G, et al. Comparison of PSA relapsefree survival in patients treated with ultra-high-dose IMRT versus combination HDR brachytherapy and IMRT. Brachytherapy. 2010 Oct; 9(4):313-318. [PubMed: 20685176]

77. van Elmpt W, De RD, van der Salm A, Lakeman A, van der Stoep J, Emans D, et al. The PETboost randomised phase II dose-escalation trial in non-small cell lung cancer. Radiother Oncol. 2012 Jul; 104(1):67-71. [PubMed: 22483675]

78. Berwouts D, Olteanu LA, Duprez F, Vercauteren T, De GW, De NW, et al. Three-phase adaptive dose-painting-by-numbers for head-and-neck cancer: initial results of the phase I clinical trial. Radiother Oncol. 2013 Jun; 107(3):310-316. [PubMed: 23647760] 


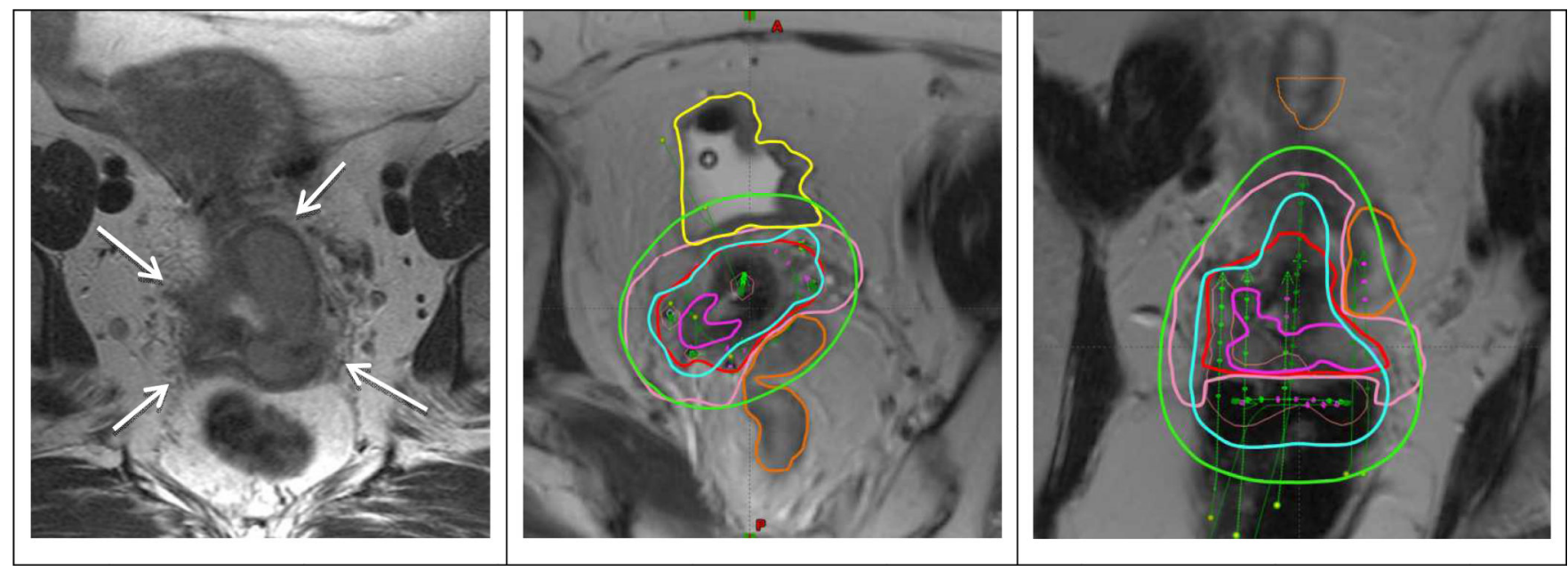

Fig 1.

Patient with FIGO stage IIIB treated with EBRT and 2 fractions of PDR MRI-guided brachytherapy. Left panel shows transverse MRI at time of diagnosis with parametrial proximal involvement (left) and to the pelvic wall (right). At time of brachytherapy there was still residual parametrial disease (left proximal and right distal). A combined intracavitary/interstitial applicator (5 needles) was used. Middle and right panel show paratransverse and coronol MRI at time of brachytherapy with the applicator in situ. The volumes are: residual GTV (magenta), $\mathrm{CTV}_{\mathrm{HR}}$ (red), $\mathrm{CTV}_{\mathrm{IR}}$ (pink), bladder (yellow) and sigmoid (orange). Isodoses $15 \mathrm{~Gy}$ (cyan) and $7.5 \mathrm{~Gy}$ (green) correspond to $84 \mathrm{~Gy}$ and $60 \mathrm{~Gy}$ in terms of total EBRT and brachytherapy EQD2. 


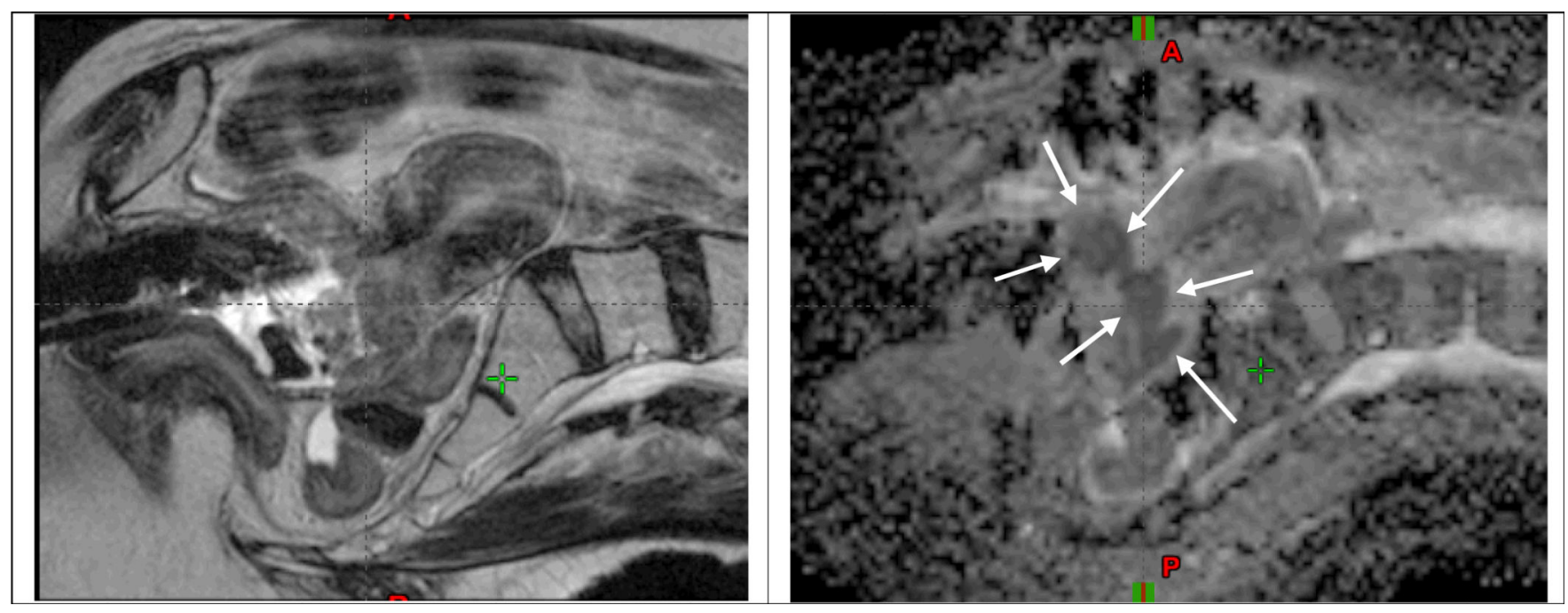

Fig 2.

MRI at time of brachytherapy for a locally advanced cervical cancer patient with stage IB2 disease treated at Dept of Radiation Oncology, Washington University, St. Louis. Left and right panel show sagittal T2w and ADC images, respectively, obtained at 4 . fraction of brachytherapy with the intracavitary applicator in situ. At the time of imaging 13 fractions of IMRT had been delivered with an integrated midline blocking as well as 3 fractions of brachytherapy of $6.5 \mathrm{~Gy}$ to point A. A significant residual GTV mass is clearly identified in the cervix region on the ADC map (arrows). The bright signal regions on the T2w image indicate residual GTV, but appear with less clear borders towards the surrounding tissue as compared with the ADC map. 

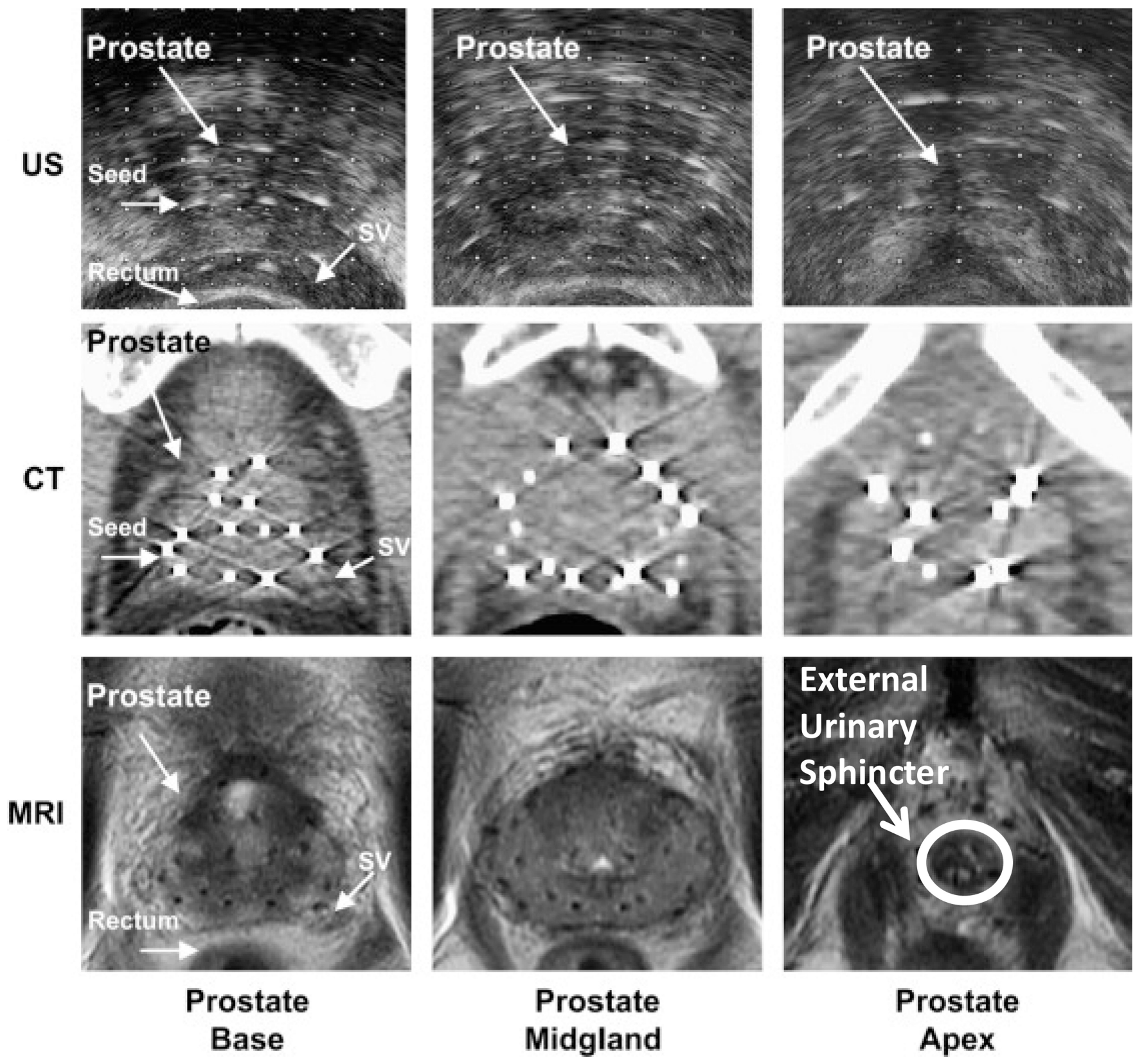

\section{Prostate Apex}

Fig 3.

Ultrasound (US), CT, and MRI images of the base, midgland, and apex of the prostate following LDR brachytherapy. MRI has superior soft tissue delineation of the prostate over ultrasound and CT. Urinary irritation and bother symptoms, which are more common in prostate brachytherapy, may be reduced with better anatomic delineation of the external urinary sphincter (indicated in bottom right) during simulation and treatment planning. Additionally, better anatomic delineation of the apex, base, neurovascular bundles, bladder neck, and intraprostatic ejaculatory ducts may also improve disease outcomes and reduce treatment related morbidity. 


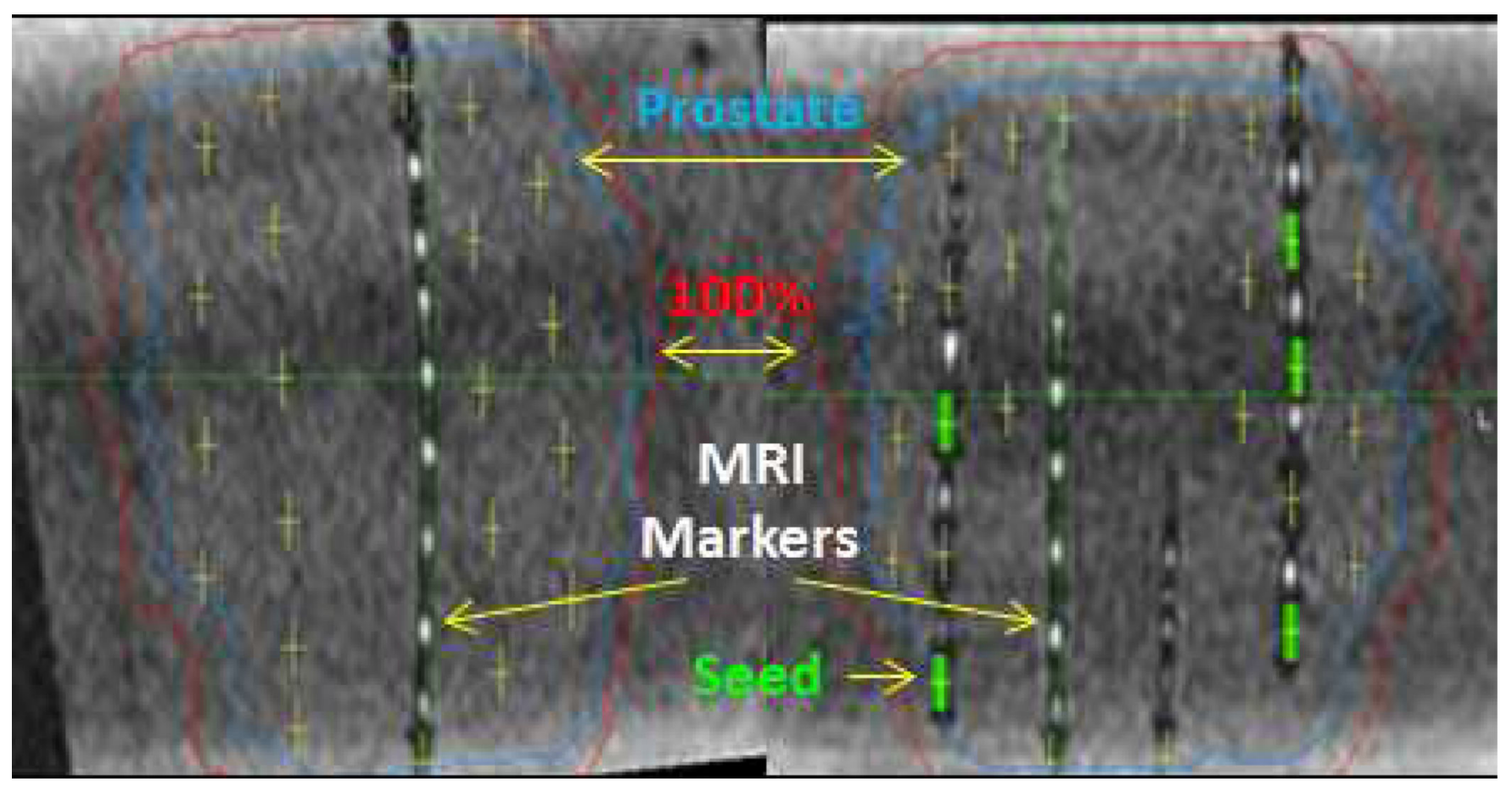

Fig 4.

MRI post-implant dosimetry in prostate phantom using C4 MRI markers within strands with I-125 dummy (i.e. non-radioactive) seeds. The positive contrast MRI markers facilitate the localization of the implanted negative contrast I-125 titatium seeds for post-implant MRIbased dosimetry. 


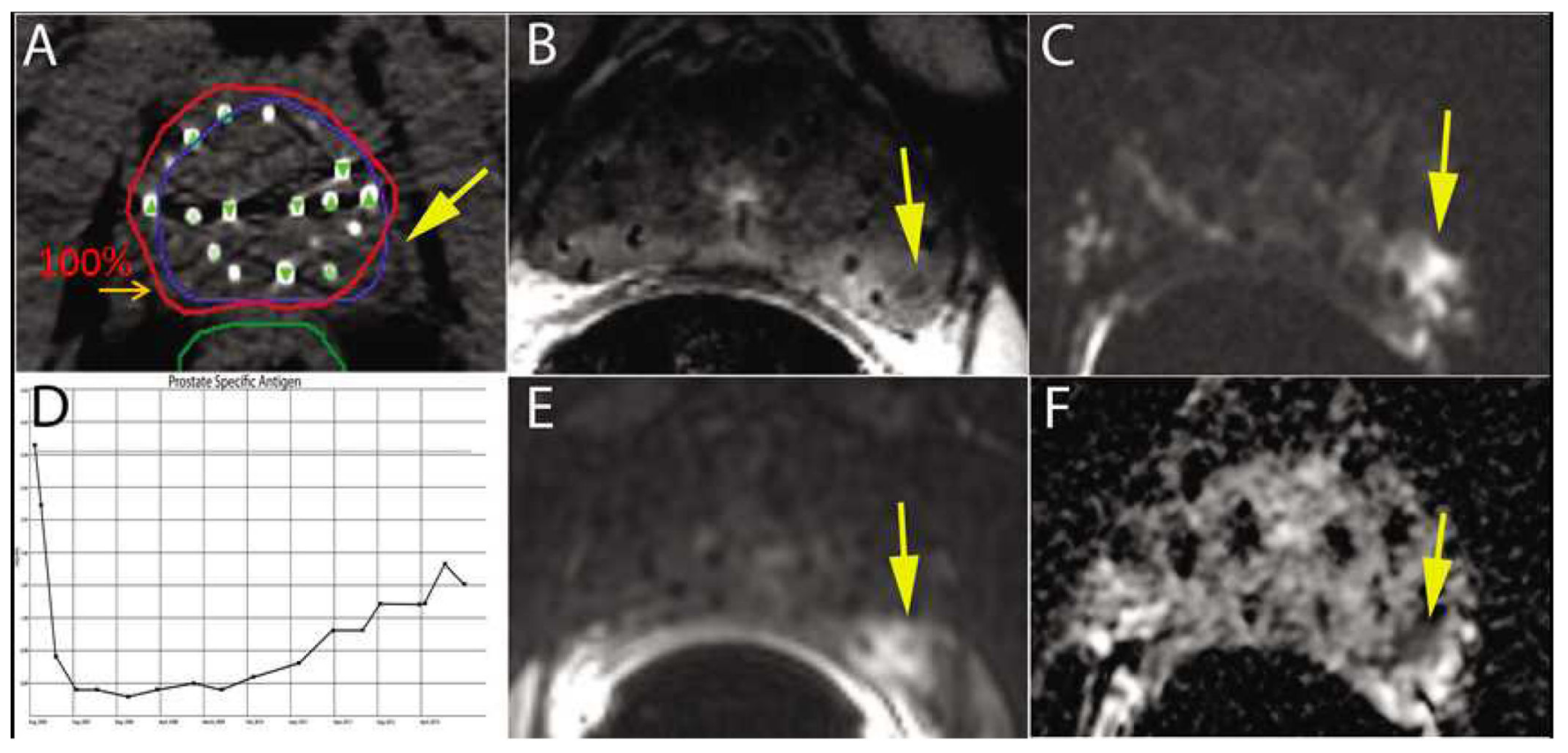

Fig 5.

A 75 yo male presented with a small nodule at the left base of the gland (i.e. clinical T2a), PSA of $6 \mathrm{ng} / \mathrm{ml}$, and Gleason Score (GS) of $7(3+4)$ and was treated with a prostate brachytherapy implant alone to 144 Gy with I-125 (A). Post-implant dosimetry demonstrated a V100=97\% and a D90=177 Gy, however, the left midgland was not covered with the $100 \%$ isodose line ( A). The patient's PSA reached a nadir of $0.3 \mathrm{ng} / \mathrm{ml}$ eighteen months after the implant. Six years after treatment he had a PSA of $2.3 \mathrm{ng} / \mathrm{ml}$ with a PSA doubling time greater than 12 months (D). Multiparametric 1.5T MRI including T2W (B), DWI (C), DCE (E), and ADC maps (F) localized the recurrence at the left midgland.

Metastatic workup was negative. Biopsy of the left midgland confirmed adenocarcinoma with a GS of $7(4+3)$. 